\title{
PRODUÇÃO E DISTRIBUIÇÃO DE COMPOSTO ORGÂNICO: REUTILIZANDO OS RESÍDUOS VERDES DO SEMIÁRIDO COM PRÁTICAS SUSTENTAVÉIS
}

\section{PRODUCTION AND DISTRIBUTION OF ORGANIC COMPOUND: REUSE OF GREEN WASTE FROM SEMIARID WITH SUSTAINABLE PRACTICES}

\author{
José Aliff Rozeno da Silva ${ }^{1}$; Gislayne Kayne Gomes da Cruz ${ }^{2}$; Manoel Modesto dos Santos \\ Neto $^{3}$ Valter Silva Ferreira ${ }^{4}$; Frederico Campos Pereira ${ }^{5}$
}

DOI: https://doi.org/10.31692/978-65-991061-7-0.14-20

\begin{abstract}
RESUMO
A compostagem é um processo de decomposição da matéria orgânica, realizado pelos agentes decompositores (bactérias, fungos, insetos e outros microrganismos). O composto orgânico é o material obtido através da compostagem, é considerado um adubo orgânico. Para obtenção do adubo ou composto, nas condições do Semiárido, em média, leva-se de 90 a 120 dias. Os resíduos orgânicos (também conhecido como lixo verde), representam cerca de $50 \%$ dos resíduos urbanos, gerados no Brasil. Esses resíduos podem ser reciclados através de processos como o da compostagem. Um Exemplo é a cidade de Picuí-PB, localizada no Seridó Oriental Paraibano, em que por meio da parceria entre a Prefeitura Municipal e o Instituto Federal da Paraíba que possui um projeto de tratamento específico dos resíduos orgânicos do município. O projeto é desenvolvido pelo NEA (Núcleo de Estudos em Agroecologia) do Instituto Federal de Educação, Ciência e Tecnologia da Paraíba - Campus Picuí. O objetivo do trabalho é analisar a atividade da compostagem no município, como produção e distribuição e seus benefícios causados na região. Já foram feitas 44 pilhas, das quais 17 foram peneiradas com produção de $2.300 \mathrm{Kg}$ de composto orgânico. Toda produção foi destinada para projetos, TCC'S e relatórios dos próprios alunos IFPB e da Prefeitura de Picuí onde a mesma distribui o composto em pequenas comunidades e para alguns agricultores da região, onde os mesmos usam em suas próprias culturas do Curimataú e Seridó Paraibano. O Semiárido necessita de Núcleos de pesquisa que incentive a práticas de projetos de Extensão, Pesquisa e Inovação que possibilitem, por meios de técnicas sustentáveis uma melhor produção na região aos agricultores. A atividade da compostagem é viável no Semiárido e pode ser implantada em qualquer região do Brasil.
\end{abstract}

PALAVRAS-CHAVE: compostagem, decomposição, adubo, Semiárido, sustentabilidade.

ABSTRACT: Composting is a process of decomposition of organic matter by decomposing agents (bacteria, fungi, insects and other microorganisms). The organic compound is the material obtained through composting, it is considered an organic fertilizer. To obtain the fertilizer, in the conditions of the Semiarid, on average, it takes from 90 to 120 days. Organic waste (also known as green waste) accounts for about 50\% of urban waste generated in Brazil. These residues can be recycled through processes such as composting. One example is the city of Picuí-PB, located in the Seridó Oriental Paraibano, where through a partnership between the City Hall and the Federal Institute of Paraíba has a specific treatment project for the municipal organic waste. The project is developed by the NEA (Nucleus of Studies in Agroecology) of the Federal Institute of Education, Science and Technology of Paraíba -

${ }^{1}$ CST em Agroecologia, Instituto Federal campus Picuí, E-mail: aliffrozeno.agro@gmail.com

${ }^{2}$ CST em Agroecologia, Instituto Federal campus Picuí, E-mail: gislayne.kayne@academico.ifpb.edu.br

${ }^{3} \mathrm{CST}$ em Agroecologia, Instituto Federal campus Picuí, E-mail: valtersilvanfpb@gmail.com

${ }^{4} \mathrm{CST}$ em Agroecologia, Instituto Federal campus Picuí, E-mail: modesto_nf@ hotmail.com

${ }^{5}$ Prof. CST em Agroecologia do IFPB Campus- Picuí, E-mail:fredcampos2000@ yahoo.com.br 
Campus Picuí. The objective of this work is to analyze the composting activity in the municipality and its benefits caused in the region. A total of 44 piles have been made, of which 17 were sieved with production of $2,300 \mathrm{~kg}$ of organic compound. All production was destined for projects of the IFPB and of the Municipality of Picuí where it distributes the compound in small communities and some farmers of the region of the Curimataú and Seridó Paraibano. The Semiarid Region needs Nucleus that encourages the practices of Extension, Research and Innovation projects that, by means of sustainable techniques, allow a better production in the region to the farmers. Composting activity is feasible in the semi-arid region and can be deployed in any region.

KEYWORDS: composting, decomposition, fertilizer, Semi-arid, sustainability

\section{INTRODUÇÃO}

O “Projeto Compostagem” iniciou em 2012, no IFPB - Campus Picuí, desenvolvido pelo NEA (Núcleo de Estudos em Agroecologia). Ainda em 2012, o projeto firmou parceria com a Prefeitura Municipal de Picuí (PMP), onde a mesma fornecia o lixo verde, que era transportado até o Campus. Toda a atividade era realizada pelos membros do núcleo, porém a produção de composto orgânico era pouca.

O projeto continuou e todo o composto era utilizado no próprio Campus. Mas o objetivo era montar um centro de compostagem, para produzir em grande escala, visando o envolvimento da comunidade em sistemas produtivos que promovam a visão sobre os modos de produção da Agroecologia, com foco no Semiárido.

No mês de abril de 2017, foi assinado o termo de cooperação técnica, entre o NEA/IFPB e a Prefeitura Municipal de Picuí, onde foi concretizado o Centro de Compostagem. Dessa forma, a prefeitura disponibiliza o local e matéria-prima para a realização do projeto, enquanto o NEA fornece os materiais de trabalho.

A atividade de compostagem, na nova instalação, foi iniciada em maio de 2017. Desde a formação das pilhas até o peneiramento, é realizado pelos membros do NEA. A distribuição do composto fica à cargo do NEA e da Secretaria de Agricultura de Picuí.

Com isso, o objetivo do trabalho é analisar a atividade da compostagem realizada no município de Picuí-PB e seus benefícios causados nos ambientes que recebem o composto orgânico, além da importância dessa prática sustentável no Semiárido Brasileiro.

\section{FUNDAMENTAÇÃO TEÓRICA}

A compostagem é um processo de decomposição da matéria orgânica, realizado pelos agentes decompositores (bactérias, fungos, insetos e outros microrganismos). No qual, os agentes decompositores, necessitam de condições ótimas de temperatura, aeração e umidade, para realizarem o processo com eficiência (OLIVEIRA, 2004). 
O composto orgânico é o material obtido através da compostagem, sendo considerado como um adubo orgânico. O composto orgânico traz benefícios físicos, químicos e biológicos ao solo, pois melhora a estrutura, nutrição e a microbiota edáfica. Para obter o adubo orgânico, em média, leva-se de 90 a 120 dias. Porém, deve-se levar em consideração a região, a matéria-prima utilizada na atividade e todo o manejo, tendo ciência disso, o processo pode ser acelerado ou retardado.

Os resíduos orgânicos (também conhecido como lixo verde), representam cerca de $50 \%$ dos resíduos urbanos, gerados no Brasil. Esses resíduos podem ser reciclados através de processos como o da compostagem, desde a escala doméstica até a industrial. Essa utilização é bastante viável, visto que a atividade da compostagem não necessita de grandes exigências tecnológicas e de recursos financeiros exorbitantes. Além disso, se torna um instrumento de educação ambiental, com foco na sustentabilidade (MINISTÉRIO DO MEIO AMBIENTE DO BRASIL, 2017).

A cidade de Picuí-PB, localizada no Seridó Oriental Paraibano, tem um projeto de tratamento específico dos resíduos orgânicos do município. O projeto é desenvolvido pelo NEA (Núcleo de Estudos em Agroecologia) do Instituto Federal de Educação, Ciência e Tecnologia da Paraíba - Campus Picuí em parceria com a Prefeitura Municipal de Picuí. Com a utilização da técnica da compostagem, transformam as podas urbanas e os cocos verdes do comércio local, juntamente com o esterco, em composto orgânico. Essa atividade é realizada em pleno Semiárido, que é caracterizado por altas temperaturas, secas prolongadas e pluviosidade baixa $(400 \mathrm{~mm} / \mathrm{ano})$.

\section{METODOLOGIA}

O trabalho foi realizado durante os meses de setembro e outubro de 2018, no Instituto Federal de Educação, Ciência e Tecnologia da Paraíba (IFPB) - Campus Picuí e no Centro Municipal de Compostagem de Picuí-PB. Foi levantado o histórico de como iniciou o "Projeto Compostagem", do NEA (Núcleo de estudos em Agroecologia) e no Centro Municipal de Compostagem, foi acompanhada a produção e a distribuição do composto orgânico.

\section{RESULTADOS E DISCUSSÃO}

Antes de iniciar a formação das leiras, as podas e o coco verde são triturados em uma máquina de trituração, pois o material triturado facilita todo o processo de compostagem. $\mathrm{O}$ fornecimento da matéria prima em partículas menores auxilia na decomposição feita pelo 
agente decompositores e na entrada de oxigênio nas pilhas. As leiras possuem tamanho de 1,20 M de altura por 2,00 M de comprimento. Para formaras leiras, é necessário que 70\% de sua composição seja de material vegetal (folhas e coco verde triturado) e $30 \%$ de esterco, para que ocorra o equilíbrio de Carbono e Nitrogênio, dois nutrientes essenciais para todo o processo. As camadas de material vegetal e de esterco são sobrepostas de maneira intercalada, sendo que a primeira e última camada é de material verde.

A pilhas de composto necessitam de água, é importante salientar que, as leiras devem estar úmidas, não podem estar encharcadas nem secas. $\mathrm{O}$ umedecimento aconteceu duas vezes por semana, logo após umedecer, as pilhas foram cobertas por uma lona de plástico, afim de manter a umidade das mesmas, já que no Semiárido o índice de evaporação é elevado. Com intuito de garantir a aeração nas pilhas, ocorreram os reviramentos das leiras, a cada 15 dias, além disso, o reviramento também auxilia na mistura dos materiais decompostos e não decompostos, facilitando o trabalho dos microrganismos.

De 117 a 179 dias, como mostra a Tabela 1, ocorreu o peneiramento das leiras, obtendo-se $2.300 \mathrm{~kg}$ em 17 pilhas peneiradas (Tabela 2).

Tabela-1: Dados individuais das leiras peneiradas

\begin{tabular}{|c|c|c|c|c|}
\hline Leira & Formação & Peneiramento & $\begin{array}{c}\text { Total } \\
\text { (dias) }\end{array}$ & Composto \\
\hline 1 & $02 / 05 / 2018$ & $27 / 08 / 2018$ & 117 & $300 \mathrm{Kg}$ \\
\hline 2 & $04 / 04 / 2018$ & $30 / 09 / 2018$ & 179 & $220 \mathrm{Kg}$ \\
\hline 3 & $09 / 04 / 2018$ & $31 / 09 / 2018$ & 179 & $150 \mathrm{Kg}$ \\
\hline 4 & $12 / 04 / 2018$ & $10 / 09 / 2018$ & 151 & $400 \mathrm{Kg}$ \\
\hline 5 & $16 / 04 / 2018$ & $19 / 09 / 2018$ & 156 & $250 \mathrm{Kg}$ \\
\hline 7 & $25 / 04 / 2017$ & $26 / 09 / 2018$ & 154 & $200 \mathrm{Kg}$ \\
\hline 8 & $25 / 04 / 2017$ & $24 / 09 / 2018$ & 152 & $150 \mathrm{Kg}$ \\
\hline 9 & $30 / 04 / 2017$ & $05 / 09 / 2018$ & 128 & $200 \mathrm{Kg}$ \\
\hline 10 & $01 / 05 / 2017$ & $26 / 08 / 2018$ & 117 & $230 \mathrm{Kg}$ \\
\hline 11 & $20 / 05 / 2017$ & $07 / 10 / 2018$ & 140 & $200 \mathrm{Kg}$ \\
\hline
\end{tabular}

Fonte: NEA, 2018. 
Tabela-1: Produção de Composto Orgânico

\begin{tabular}{|c|c|c|c|}
\hline Total de leiras feitas & $\begin{array}{c}\text { Total de leiras } \\
\text { peneiradas }\end{array}$ & Composto $(\mathrm{kg})$ & Média (Kg/LP) \\
\hline 44 & 17 & 2.300 & 220 \\
\hline
\end{tabular}

Fonte: NEA, 2018.

Algumas leiras ultrapassaram o período de dias "padrão" para a atividade da compostagem. Porém, atribuem-se a esse fator, o material utilizado nas pilhas, o manejo e as condições climáticas da região. A casca do coco verde, foi utilizado em algumas leiras, esse tipo de resíduo verde leva mais tempo para ser decomposto, em virtude de ser um material mais grosseiro.

Algumas pilhas foram aumentadas ao decorrer do tempo, tendo como objetivo uma maior produção de composto, porém essa prática, atrasa o processo. A região também afetou no processo de decomposição, já que os agentes decompositores necessitam de umidade adequada, e no Semiárido o índice de evaporação é alto, o que ocasionou na evaporação da água das leiras.

Para fomentar o desenvolvimento sustentável e o envolvimento da comunidade, no projeto e na Agroecologia, o composto orgânico é distribuído para vários fins, como mostra a figura 1 .

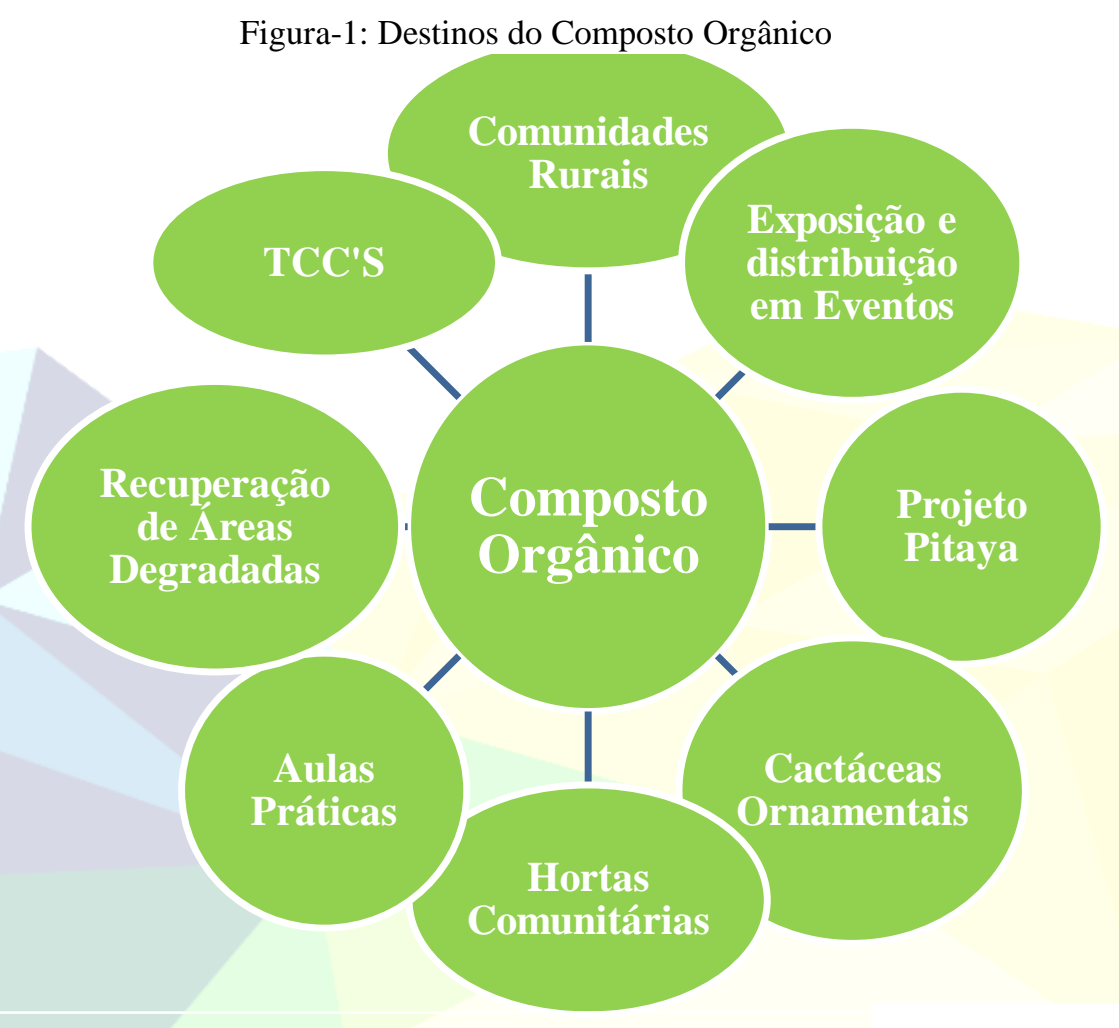

Fonte: NEA, 2018.

Várias atividades e projetos no IFPB e no munícipio de Picuí estão sendo beneficiadas 
com o projeto Compostagem. É de grande importância para a região do Semiárido, alternativas de produção que visem o desenvolvimento das comunidades rurais e urbanas, com práticas Agroecológicas e de valorização da região do SAB.

\section{CONCLUSÕES}

Conclui-se que, a prática da compostagem é totalmente viável no Semiárido e pode ser introduzida em todas as regiões. A utilização do lixo verde é uma alternativa para produzir composto orgânico, propiciando a conscientização da sustentabilidade popular e fomentando a Agroecologia. O composto orgânico tem diversos destinos, facilitando e ajudando na produção nas localidades, diversos ambientes recebem o adubo e várias atividades estão sendo beneficiadas com o projeto, Além de vários Relatos de pequenos Agricultores onde os mesmos parabeniza a eficiência e qualidade do adubo, como também a capacidade do NEA ( Núcleo de estudos em agroecologia) em facilitar a troca de conhecimento entre Graduandos e Agricultores.

\section{REFERÊNCIAS}

OLIVEIRA, Francisco Nelsieudes Sombra; LIMA, Hermínio José Moreira; CAJAZEIRA, João Paulo. Uso de compostagem em sistemas agrícolas orgânicos. Embrapa Agroindústria Tropical. Fortaleza, 2004. 17 p.

MINISTÉRIO DO MEIO AMBIENTE DO BRASIL. Compostagem doméstica, comunitária e institucional de resíduos orgânicos: manual de orientação. Ministério do Meio Ambiente, Centro de Estudos e Promoção da Agricultura de Grupo, Serviço Social do Comércio. Brasília, DF, 2017. 68 p.

MATOS, Antonio T. de. et al. Compostagem de alguns resíduos orgânicos, utilizando-se águas residuárias da suinocultura como fonte de nitrogênio. Revista Brasileira de Engenharia Agrícola e Ambiental, Campina Grande-PB, v.2, n.2, p.199-203, 1998.

LOUREIRO, Diego Campana. et al. Compostagem e vermicompostagem de resíduos domiciliares com esterco bovino para a produção de insumo orgânico. Pesq. Agropec. Bras., Brasília, v.42, n.7, p.1043-1048, jul. 2007.

HEBERTS, R. A. et al. Compostagem de resíduos sólidos orgânicos: aspectos biotecnológicos. Revista saúde e ambiente. v.6, n.1, jun. 2005.

ORRICO JÚNIOR, Marco A. P.; ORRICO, Ana C. A.; LUCAS JÚNIOR, Jorge de. Compostagem dos resíduos da produção avícola: cama de frangos e carcaças de aves. Eng. Agríc.; Jaboticabal, v.30, n.3, p.538-545, maio/jun. 2010.

FIORI, Marciane Gorete Silvestro; SCHOENHALS, Marlise; FOLLADOR, Franciele Aní Caovilla. Análise da evolução tempo-eficiência de duas composições de resíduos 
PRODUÇÃO E DISTRIBUIÇÃO DE COMPOSTO ORGÂNICO: REUTILIZANDO OS RESÍDUOS

agroindustriais no processo de compostagem aeróbia. Engenharia Ambiental. Espírito Santo do Pinhal, v.5, n.3, p.178-191, set/dez 2008. 